\title{
Factors affecting the performance of microbial fuel cells for sulfur pollutants removal
}

\author{
Feng Zhao $^{\mathrm{a}^{*}}$, Nelli Rahunen ${ }^{\mathrm{b}}$, John R. Varcoe ${ }^{\mathrm{a}}$, Alexander J. Roberts ${ }^{\mathrm{a}}$, \\ Claudio Avignone-Rossa ${ }^{\mathrm{b}}$, Alfred E. Thumser ${ }^{\mathrm{b}}$, Robert C.T. Slade ${ }^{\mathrm{a}^{*}}$ \\ ${ }^{a}$ Chemical Sciences, ${ }^{b}$ Biological Sciences, \\ University of Surrey, Guildford, GU2 7XH, United Kingdom
}

${ }^{*}$ Corresponding author phone: +44 1483 682588; fax: +44 1483 686851; E-mail: R.Slade@surrey.ac.uk; f.zhao@surrey.ac.uk 


\begin{abstract}
:
A microbial fuel cell (MFC) has been developed for removal of sulfur-based pollutants and can be used for simultaneous wastewater treatment and electricity generation. This fuel cell uses an activated carbon cloth + carbon fibre veil composite anode, air-breathing dual cathodes and the sulfate-reducing species Desulfovibrio desulfuricans. $1.16 \mathrm{~g} \mathrm{dm}^{-3}$ sulfite and $0.97 \mathrm{~g} \mathrm{dm}^{-3}$ thiosulfate were removed from the wastewater at $22^{\circ} \mathrm{C}$, representing sulfite and thiosulfate removal conversions of $91 \%$ and $86 \%$, respectively. The anode potential was controlled by the concentration of sulfide in the compartment. The performance of the cathode assembly was affected by the concentration of protons in the cation-exchanging ionomer with which the electrocatalyst is co-bound at the threephase (air, catalyst, support) boundary.
\end{abstract}

Keywords: Microbial fuel cell; Anode; Cathode; Sulfur pollutants; bacteria 


\section{Introduction}

Waste treatment and electricity generation are both key issues for sustainable modern societies. Microbial fuel cells (MFCs) are attracting increased attention, driven by the demands for clean and renewable energy resources, and especially for their potential to directly recover electricity from various wastewaters.

Sulfite and thiosulfate pollutants are commonly found in wastewaters, which are generated by processes such as dye and detergent manufacture, bleach and photographic industries etc.; these pollutants cause numerous adverse effects e.g. generating corrosive acid rain and toxic acidic gas, destroying aquatic ecosystems (Lens et al., 2000). Sulfatereducing bacteria (SRB), which use sulfur compounds as energy source, are a diverse group of bacteria widely distributed in anaerobic marine and terrestrial environments (Widdel et al., 1984). SRBs play a key role in the global sulfur cycle e.g. removing much of the approximately $10^{11} \mathrm{~kg}$ of oceanic sulfate that is discharged each year from river runoff (Battersby et al., 1988). MFCs researching use of SRB have been reported (Habermann et al 1991; Cooney et al 1996). Recently, we have clarified the anode reaction mechanism: the generation of electricity is mainly from the oxidation of biologically produced sulfide to elemental sulfur (soluble polysulfides) (Zhao et al., 2008). An enhanced power output and a high removal efficiency of sulfate were achieved with the use of activated carbon cloth (ACC) as anode. There has been no wider report of MFCs including investigation of the removal of sulfite and thiosulfate, major environmental pollutants and ubiquitous in wastewaters.

In comparison to other abiotic cathode reactions, the reduction of molecular oxygen is the best choice both for chemical fuel cells and for MFCs, because the reduction product is clean, non-polluting $\mathrm{H}_{2} \mathrm{O}$. However, MFC operation differs from that of chemical fuel cells; MFCs needlow ion concentrations and neutral $\mathrm{pH}$, the normally optimal conditions 
for metabolic activity of microbes. The potential of a cathode immersed in air-purged solution has been reported (Zhao et al., 2005, 2006), and the performance for oxygen reduction reaction is strongly influenced by proton and phosphate ion concentrations. Oxygen reduction potentials can be calculated via the Nernst equation. When $T=22{ }^{\circ} \mathrm{C}$ and the partial pressure of oxygen $p=0.21 \mathrm{~atm}$, that potential is given by:

$$
E_{\text {ORR }} / V=1.22-0.058 p H \quad \text { equation (1) }
$$

The "ideal" cathode potential is $0.81 \mathrm{~V}$ when the $\mathrm{pH}$ of solution is 7.0 , but in practice it lies in the range $0.5-0.6 \mathrm{~V}$; the values are always lower than the theoretical value due to mixed potential effects and to the presence of contaminating species. Two types of airbreathing cathodes have been reported recently with either a membrane-less cathode or a membrane cathode assembly (Liu et al., 2004; Cheng et al., 2006). In related studies, airbreathing cathodes, where atmospheric oxygen serves as oxidant, sometimes showed different performance with immersed cathodes: lower potentials e.g. $0.027 \mathrm{~V}$ (Fan et al., 2007; Liu et al., 2004). Hence there is an issue. Why did these air-breathing cathodes show very different performance with same operational conditions? The factors affecting air-breathing cathode potentials need to be further investigated.

In this study, Desulfovibrio desulfuricans was used for sulfite and thiosulfate reduction in artificial wastewater; the metabolism of SRBs is not restricted to sulfate reduction and many species can produce sulfide by reduction of sulfite and thiosulfate (Dannenberg et al., 1992). A one chamber, air-breathing dual cathode MFC configuration was designed for obtaining high power outputs and achieving efficient sulfite and thiosulfate removal. The factors affecting the potentials of the anode and the cathode assembly were studied, which are very important for MFC's performance. 


\section{Experimental section}

\subsection{Microbial culture and artificial wastewater.}

Desulfovibrio desulfuricans was purchased from the German Collection of Microorganisms and Cell Cultures, Braunschweig, Germany. D. desulfuricans cultures were elaborated as described previously (Zhao et al., 2008).

The artificial wastewater used in the MFC experiments was composed of $\left(\right.$ per $\left.\mathrm{dm}^{3}\right)$ : sodium lactate $(8.0 \mathrm{~g})$, yeast extract $(1.0 \mathrm{~g}), \mathrm{Na}_{2} \mathrm{SO}_{3}(2.0 \mathrm{~g}), \mathrm{Na}_{2} \mathrm{~S}_{2} \mathrm{O}_{3} .5 \mathrm{H}_{2} \mathrm{O}(2.5 \mathrm{~g})$, $\mathrm{FeSO}_{4} .7 \mathrm{H}_{2} \mathrm{O}(0.004 \mathrm{~g}), \mathrm{MgSO}_{4} \cdot 7 \mathrm{H}_{2} \mathrm{O}(0.06 \mathrm{~g}), \mathrm{KH}_{2} \mathrm{PO}_{4}(0.5 \mathrm{~g}), \mathrm{NH}_{4} \mathrm{Cl}(1 \mathrm{~g}), \mathrm{CaCl}_{2} \cdot 6 \mathrm{H}_{2} \mathrm{O}$ $(0.06 \mathrm{~g})$, sodium citrate $(0.3 \mathrm{~g})$, sodium thioglycolate $(0.1 \mathrm{~g})$ and ascorbic acid $(0.1 \mathrm{~g})$. The wastewater $\mathrm{pH}$ was adjusted to 7.5 with $\mathrm{NaOH}\left(\mathrm{aq}, 2 \mathrm{~mol} \mathrm{dm}^{-3}\right.$ ) prior to autoclaving at $121^{\circ} \mathrm{C}$ for $15 \mathrm{~min}$.

\subsection{Ion chromatography for sulfur compounds concentrations.}

A Dionex DX-100 ion chromatograph with an ED 40 electrochemical detector was used to determine the concentration of sulfate, sulfite and thiosulfate anions in the wastewater after $22 \mathrm{~h}$ of MFC operation. Samples from the chamber were collected and filtered using a syringe filter of pore size $0.45 \mu \mathrm{m}$ prior to the test. The eluent was $\mathrm{Na}_{2} \mathrm{CO}_{3}(3.5 \mathrm{mmol}$ $\left.\mathrm{dm}^{-3}\right)+\mathrm{NaHCO}_{3}\left(1.0 \mathrm{mmol} \mathrm{dm}{ }^{-3}\right)$, a buffer solution.

\subsection{Anode surface area and pore size measurements.}

Activated carbon cloth (CTEX-20) was obtained from MAST Carbon Advanced Products Ltd. UK. Carbon fibre veil (CFV) was supplied by Technical Fibre Products Limited, UK. $\mathrm{ACC}$ and $\mathrm{CFV}$ samples for nitrogen sorption analysis at $77 \mathrm{~K}$ were first out-gassed at $60^{\circ} \mathrm{C}$ for 48 hours using a Micromeritics Flowprep 060 before transferring to a Micromeritics Gemini V Surface Area and Pore Size Analyser. Isotherms were used to 
calculate the specific surface areas through application of the BET model (Brunauer et al., 1938), a widely adopted data reduction technique linking the amount of physically adsorbed gas and specific surface area of a material; the total pore volume and the pore size distributions were calculated using the BJH method (Barrett et al., 1951).

\subsection{Scanning Electron Microscopy.}

A Hitachi S2300 SEM was used to characterize the anode (pre-test and post-test) with an acceleration voltage of $10 \mathrm{kV}$. For pre-test, ACC was cut into pieces of $0.5-1.0 \mathrm{~cm}^{2}$ in size. For post-test, the anode was removed from the anaerobic chamber after MFC operation, and stored overnight at $30^{\circ} \mathrm{C}$ in air.

\subsection{Electrochemical measurements.}

ELAT cathode material (E-TEK division of BASF) was coated with Nafion ionomer (5\% dispersion) and dried in air to a constant Nafion loading of $0.5 \mathrm{mg} \mathrm{cm}^{-2}$. The air-breathing cathode assembly was fabricated by pressing the ELAT to a Nafion-115 membrane with $120 \mathrm{~kg} \mathrm{~cm}^{-2}$ force at $135^{\circ} \mathrm{C}$ for $3 \mathrm{~min}$ as described previously (Zhao et al., 2008). Galvanodynamic polarization experiments of the cathode assembly were performed as before (Zhao et al., 2006). Open circuit potentials (OCP) of the anodes and the cathode assembly as a function of time were individually recorded (all versus a $\mathrm{Ag} / \mathrm{AgCl}$ electrode as reference) using a digital multi-meter (Integra 2700 series with 7700 multiplexer, Keithley Instruments, Inc., U.S.A.) interfaced to a personal computer for data collection. For OCP studies of cathode: the cathode assembly was placed at one end of MFC chamber with the electrode in contact with the air supply (this constituting an air-breathing cathode system) and the membrane in contact with bacteria-free phosphate buffer $(\mathrm{pH} \mathrm{7.0,50}$

mmol $\mathrm{dm}^{-3}$ ) in the compartment; a $\mathrm{Ag} / \mathrm{AgCl}$ reference electrode was immersed in the 
buffer. For OCP tests of anodes, $\mathrm{ACC}$ and $\mathrm{CFV}$ anodes and a $\mathrm{Ag} / \mathrm{AgCl}$ reference electrode were immersed in artificial wastewater.

The ohmic internal resistance (mixture of electronic/ionic and contact resistances) (Varcoe et al., 2006) of the MFC and the electronic conductivity of the ACC and the CFV were determined using electrochemical impedance spectrometry using a Solartron Analytical 1260 frequency response analyser in conjunction with a Solartron Analytical 1287 potentiostat/galvanostat in the frequency range $1 \mathrm{MHz}-10 \mathrm{~Hz}$ and with a perturbation signal of $10 \mathrm{mV}$ rms. The electronic conductivity of the ACC and the CFV anode materials were measured with two parallel probes (Zhao et al., 2004a, 2004b) (two copper electrodes of diameter $7.0 \mathrm{~mm})$ in a "sandwich" configuration $(\mathrm{Cu} / \mathrm{ACC} / \mathrm{Cu}$ or $\mathrm{Cu} / \mathrm{CFV} / \mathrm{Cu}$ ) held together by a spring in a test cell to ensure constant and reproducible contact pressure.

\subsection{Microbial fuel cell construction and operation.}

A single chamber, air-breathing dual cathode assembly, and continuous flow type MFC was constructed in Perspex as shown in Fig. 1. The ACC $\left(60 \mathrm{~cm}^{2}\right)$ and CFV $\left(80 \mathrm{~cm}^{2}\right)$ were folded together as the composite anode, and a long titanium wire was knitted into the anode to provide a connection terminal. Taking into account the anode surface area, two air-breathing cathode assemblies (each with geometric area of $9 \mathrm{~cm}^{2}$ ) were used. A $\mathrm{Ag} / \mathrm{AgCl}$ reference electrode was used to record the individual electrode potential. Rubber gaskets were used to prevent leakage. The chamber was $2 \mathrm{~cm}$ deep, $3 \mathrm{~cm}$ wide and $3 \mathrm{~cm}$

high (volume $18 \mathrm{~cm}^{3}$ ), and the total liquid volume was $9 \mathrm{~cm}^{3}$ after the anode was placed in the chamber.

For fuel cell operation, the MFC was operated in a recycled flow batch mode: $1 \mathrm{~cm}^{3}$ of D. desulfuricans culture was inoculated into $100 \mathrm{~cm}^{3}$ artificial wastewater in a serum 
bottle for 3 days at $22^{\circ} \mathrm{C}$. The wastewater was then continuously pumped from the bottle to the chamber. The MFC potential and current were recorded with an external load of 20 ohm.

All electrochemical experiments and MFC operations reported in this paper were carried out at $22.0 \pm 0.5^{\circ} \mathrm{C}$, and all potentials of three-electrode systems were converted to the standard hydrogen electrode (SHE) reference scale unless otherwise stated. Fuel cell voltage and current were tested in 2-electrode mode by connection of anode and cathode across the load.

\section{Results and Discussions}

\subsection{Characterization of $A C C$ and $C F V$ anode materials.}

Surface area and morphology of anodes are important for MFC performance, especially when elemental sulfur is to be deposited on the anode. The SEM images show that ACC is similar in form to industrial textiles on a macroscopic scale (Fig. 2a) and is composed of multi-fibre threads (Fig. 2b). The inset shows the morphological structure of the individual fibres, with diameters in the range of $10-15 \mu \mathrm{m}$; ridges were observed in the axial direction and a slit cylindrical structure. BET analysis (Table 1, supporting data) yields $\mathrm{S}_{\mathrm{BET}}=1038 \mathrm{~m}^{2} \mathrm{~g}^{-1}$ for the ACC material and $\mathrm{S}_{\mathrm{BET}}<0.3 \mathrm{~m}^{2} \mathrm{~g}^{-1}$ for CFV, which indicates that ACC has massively larger micro-porosity and specific surface area compared to CFV of the same geometric area. A high surface area is important for anode performance (to slow performance losses with time) for this system where solid sulfur, one of the products of sulfide oxidation, is deposited on the anode surface.

The electrical conductivity of the electrode material has an effect on the internal resistance of the MFC. S-Table 1 (supporting data) show the electrical conductivity of compressed ACC was higher than that of CFV. However, it should be noted that the ACC 
conductivity was highly dependent on the pressure applied by the copper electrodes, ACC being composed of loosely packed multi-fibres in a textile form. When the ACC was under light pressure, the conductivity $\left(\sim 0.01 \mathrm{~S} \mathrm{~cm}^{-1}\right)$ was lower than that reported; this results from the then poorer contact between individual fibres and would be the case in a simple MFC anode. The conductivity of both materials is less than for metals, but taking into account the material thickness $(0.55 \mathrm{~mm}$ for $\mathrm{ACC}$ and $0.10 \mathrm{~mm}$ for CFT), the resistances along the thickness direction are quite low. For application as the anode in the MFC tests, the ACC was therefore folded around a single CFV sheet and held folded by a long titanium wire $(\mathrm{CFV}+\mathrm{Ti}$ then contribute to current collection feeding into the eternal circuit). The ohmic internal resistance of the MFC was $9.5 \mathrm{ohm}$, a low value in MFC studies.

\subsection{Cathode potential measurements in a half-cell.}

Fig. 3 shows the OCP of the cathode assembly measured as a function of time; the solution in the chamber in contact with the membrane was $\mathrm{pH} 7.0$ buffer. At the beginning of the test, a potential of $0.9 \mathrm{~V}$ was obtained, higher than results in previous studies $(0.027$ V and 0.31 V; Fan et al., 2007; Liu et al., 2004). This is because ELAT electrode used was coated with a film of Nafion ionomer when the cathode assembly was prepared. This is a standard procedure for chemical $\mathrm{H}_{2} /$ air PEM fuel cells to ensure enhanced catalystmembrane contact and to decrease ohmic drop at cathodes. The Nafion ionomer has perfluorinated pendant side-chains terminating in strongly acidic sulfonic groups $\left(-\mathrm{SO}_{3} \mathrm{H}\right)$. These hydrated proton exchange sites are in contact with the Pt catalyst and are extremely acidic, hence the cathode potential of $0.9 \mathrm{~V}$ was observed. In this case, the membrane cathode assembly shows better performance than that of membrane-less cathodes. 
Cations (e.g. $\left.\mathrm{Na}^{+}, \mathrm{K}^{+}\right)$in the neutral buffer are present in far higher concentration $(0.05$ mol dm$\left.{ }^{-3}\right)$ than protons $\left(10^{-7} \mathrm{~mol} \mathrm{dm}^{-3}\right)$ and will slowly diffuse through the membrane by ion exchange to the negatively charged sulfonic groups of ionomer, yielding $-\mathrm{SO}_{3}{ }^{-} \mathrm{M}^{+}$. The environment surrounding the cathode catalyst moves to higher $\mathrm{pH}$ (neutral), explaining the cathode potential decreased to $0.63 \mathrm{~V}$ at $\mathrm{t}=500 \mathrm{~h}$. The inset of Fig. 3 shows the galvanodynamic polarizations of the cathode assembly at $0 \mathrm{~h}$ and $500 \mathrm{~h}$, respectively; the current at $0.2 \mathrm{~V}$ decreased from 1.96 to $0.53 \mathrm{~mA}$, due to the decrease both of OCP and of the concentration of protons surrounding the catalyst. The potential recovered to $0.9 \mathrm{~V}$ after immersing the cathode assembly in $\mathrm{H}_{2} \mathrm{SO}_{4}(\mathrm{aq})$, as expected.

The cathode assembly in Fig. 3 was studied in OCP mode (zero current), where the drop in the potential was only driven by the exchange between cations and proton surrounding the catalysts. When a cathode assembly is used in a MFC, the cathode potential would decrease at a more rapid rate due to the additional $\mathrm{H}^{+}$loss/consumption caused by the oxygen reduction reaction (ORR). After 3 repeated recordings of power vs. current polarisation using external resistances as controlled loads, the cathodic OCP recovered to $0.50-0.66 \mathrm{~V}$, in line with the expected cathode potential in neutral solution. The results show that the acid-form Nafion ionomer initially at the catalyst allows the cathode assembly to achieve a high performance, but for MFC long-term operation a continuous supply of protons would be better.

To obtain high coulombic efficiency and to avoid bio-fouling of cathodes, different membrane types proton (Zhao et al., 2006) or cation exchange membranes (Rabaey et al., 2005), anion exchange membranes (Kim et al., 2007), bipolar membranes (Heijne et al., 2006), glass wool (Mohan et al., 2008) and nano-porous filters (Biffinger et al., 2007) have been used as separator in MFCs, but none of those membranes can prevent the cathode $\mathrm{pH}$ rising during fuel cell operation (Harnisch et al., 2008). Keeping the desired $\mathrm{pH}$ conditions 
around cathode catalysts for the ORR represents a significant research challenge, not only for cathodes immersed in air purged solutions but also for air-breathing cathodes. A comparison of the different membrane types, not considering the cost of materials, leads to the following conclusions:

- proton and other cation exchange membranes are the best choice for treatment of pollutant anions (i.e. $\mathrm{NO}_{3}^{-}, \mathrm{HS}^{-}$), both provide proton and cation transport from anode chamber to cathode part;

- anion exchange membranes are unsuitable for anionic pollutants treatment as anions easily transfer through the membrane and cross-over can happen, especially as platinum poisoning reaction will result. Moreover, $\mathrm{OH}^{-}$ions easily pass through the membrane and might lead to $\mathrm{pH}$ rise in the environment surrounding the cathode catalyst;

- extra energy is required for water splitting reaction to obtain transport of $\mathrm{H}^{+}$and $\mathrm{OH}^{-}$ions when bipolar membranes are used in MFCs; higher MFCs current is achieved and more extra energy will be required;

- membrane-less air cathodes are unsuitable for the sulfur pollutants systems because leakage of sulfide can easily occur.

A periodic cleaning of the cathode assembly may be necessary, as salt crystal formation is observed on the catalyst side of the cathode. The accumulation of salt crystals would result in blocking both oxygen diffusion and proton transport, such that the cathode performance decreases. In this study, the cathode assembly was regenerated in $\mathrm{H}_{2} \mathrm{SO}_{4}(\mathrm{aq})$ during the removal of the anode for recovery of elemental sulfur.

\subsection{Anode potential measurements in a half-cell.}


Bacterial cells can attach to surface of electrodes and form a continuous biofilm, which has an important effect on anode potential of MFCs (Aelterman et al., 2008). The OCPs for ACC and CFV versus reference electrode were recorded as a function of time in a half cell as shown in Fig. 4. Upon inoculation with $1 \mathrm{~cm}^{3} D$. desulfuricans culture, the equilibrium potentials of the ACC and the CFV were $0.09 \mathrm{~V}$ and $-0.01 \mathrm{~V}$, respectively. Both potentials shifted to negative values with time despite the differing natures of the carbon based materials $(0-56 \mathrm{~h}$ in Fig. 5). After $60 \mathrm{~h}$, the potential dropped slowly for the ACC but stabilized at approximately $-0.25 \mathrm{~V}$ in the case of CFV. As with the cathode assembly, the change of electrode potentials can also be explained by Nernstian behaviour. $p K_{l}$ for sulfide is 6.9 and the predominant species in neutral solution are therefore HS $^{-}$and $\mathrm{H}_{2} \mathrm{~S}$. It should be noted that the $\mathrm{pH}$ of the solution is an important parameter for determining the sulfide oxidation potential because a proton concentration term is required for Nernstian thermodynamics. The following oxidation potentials apply at $\mathrm{pH}$ 7.0:

$$
\begin{array}{ll}
\mathrm{H}_{2} \mathrm{~S}=\mathrm{S}+2 \mathrm{H}^{+}+2 \mathrm{e}^{-} & E^{o} / V=-0.271-0.029 \log a_{H_{2} S} \\
\mathrm{HS}^{-}=\mathrm{S}+\mathrm{H}^{+}+2 \mathrm{e}^{-} & E^{o} / V=-0.266-0.029 \log a_{H S^{-}}
\end{array}
$$

where $a$ is the activity concentration of sulfide. After inoculation into the sealed chamber, D. desulfuricans cells produce sulfide by reducing the sulfite and thiosulfate in the wastewater. The accumulation of sulfide (increase in concentration) led to the shift of the equilibrium electrode potential of both $\mathrm{ACC}$ and CFV towards more negative values according to the equations (2) and (3). However, bio-reduction pathways for the sulfur compounds are inhibited by high sulfide concentration (Reis et al., 1992). When the accumulation of sulfide reached a "breakout point", at which biological reduction of sulfate almost ceased and sulfide producing process stopped, hence the potential of the CFV electrode remained at $-0.25 \mathrm{~V}$ after $60 \mathrm{~h}$. The potential of the ACC electrode, however, slowly shifted from $-0.25 \mathrm{~V}$ at $60 \mathrm{~h}$ to $-0.27 \mathrm{~V}$ at $140 \mathrm{~h}$, the sulfide in the 
wastewater being strongly adsorbed in the ACC micropores. The higher sulfide concentration on the ACC active surface resulted in the observed potential difference of $0.02 \mathrm{~V}$ compared to that of the CFV; the more negative anode potential leads to a higher theoretical electrical energy release from the MFCs. These results indicate that ACC, with micro-porous structure (high surface area) for sulfide adsorption, is a superior material as an anode for sulfide removal with simultaneous electricity generation in a MFC.

In order to investigate if the anodic potential was affected by biofilm, D. desulfuricans was inoculated in artificial wastewater in a sealed serum bottle. After 3 days, this wastewater was pumped to the MFC; a change of anodic potential was immediately observed, and stabilized at $\sim-0.25 \mathrm{~V}$ after a few minutes. These results include little possibility for biofilm formation, because the residence time of the bacteria in the MFC was too short for the cells to attach to the anode surface. Moreover, the same change of potential can be reproduced by adding sulfide to a bacteria-free buffer. Hence, it can be concluded that the anode potential was controlled by the sulfide concentration in wastewater and not by a biofilm.

For MFCs studies, there have been no detailed mechanism studies concerning the influence of metabolites on anode potential when only inert materials (e.g. carbon cloth or graphite etc.) are used as anode. Our results indicate that redox active metabolites in solution can affect anode potential. In future studies, considerable attention will be required regarding the factors that affect electrode potential, because not only the biofilm on the electrode surface but also the metabolites in solution affect the anode potential.

\subsection{MFC performance tests.}

The biological sulfide-generating process will almost stop when the accumulation of sulfide reaches a "breakout point", but the power output of the MFC is dependent on 
sulfide concentration: the higher the concentration, the higher the power output (Zhao et al., 2008; Ieropoulos et al., 2005). It is very important to determine the "balance point" (beyond which a higher level of sulfide production will inhibit the biological reduction of sulfate), which gives the maximum power. In this study, the concentration of sulfide from metabolism was observed by anode OCP change. When the OCP reached $-0.24 \mathrm{~V}$ it indicated the concentration had nearly reached maximum $(\sim-0.26 \mathrm{~V})$; the wastewater was then pumped into the MFC chamber and a high power output was obtained. The sulfide was rapidly oxidized at the anode, causing a sharp decrease in its concentration, allowing sulfite and thiosulfate to be continuously biologically reduced and to be finally removed from the wastewater.

Based on the polarization tests with different external loads, the power output achieved a maximum value at the external load of $20 \mathrm{ohm}$; hence, this load was used to investigate the MFC performance as a function of time. Fig. 5 shows the current vs. time performance of the MFC operated in a batch mode. A maximum current of $16.1 \mathrm{~mA}$ was obtained at $500 \mathrm{~s}$, when the operation of MFC was switched from open circuit to an external load of $20 \mathrm{ohm}$. In the switching process, the cathode showed a higher potential change when compared to that for the anode, the potential change of the cathode was $0.55 \mathrm{~V}$ and for the anode potential was $0.08 \mathrm{~V}$, increasing cathode surface area could enhance power output. The current quickly dropped from $16 \mathrm{~mA}$ to $10 \mathrm{~mA}$ in the following $200 \mathrm{~s}$, then decreased more slowly as the cell voltage decreased slowly. The anode potential shift was faster than that of the cathode, resulting in a decreasing MFC voltage. A power output of $2.68 \mathrm{~mW}$ was obtained at $9.8 \mathrm{~mA}$, where the electrons at the anode were from electrochemical oxidation of sulfide. The cathode and the sulfide concentration was the major limiting factor in this process; using an anaerobic reservoir for sulfide accumulation combined with MFC technology could lead to an enhanced power output. 
When the current of MFC had decreased to $0.6 \mathrm{~mA}$, the concentration of sulfur compounds in the wastewater was detected. Table 1 shows the concentration change and the removal efficiency before and after $22 \mathrm{~h}$ of MFC operation. No sulfate was detected in the sample solution. $1.16 \mathrm{~g} \mathrm{dm}^{-3}$ sulfite and $0.97 \mathrm{~g} \mathrm{dm}^{-3}$ thiosulfate were removed from the wastewater, corresponding to conversions of $91 \%$ for sulfite and $86 \%$ for thiosulfate, respectively.

\section{Conclusions}

In this system, most sulfide was electrochemically oxidized to sulfur (polysulfides) by the anode. A small amount of sulfide was oxidized to forms with higher sulfur oxidation states (oxoanions) that could be reduced again by bacteria to sulfide, only in this case sulfide can be considered as mediator of electron transfer reaction. Elemental sulfur on anode surface might also be reduced by bacteria; sulfate and sulfite etc. may be produced by bacterial oxidation and/or disproportionation reactions. In this complex multivariate system, the results indicate the limiting factor is the slowly biological reactions.

The factors that affect the cathode and anode potentials were investigated. Compared with other membrane types, proton (cation) exchange membrane and Nafion ionomer at the catalyst enable the cathode assembly to achieve high performance. The anode performance is controlled by the sulfide concentration; this system might be useful in applications of MFC type biosensor for sulfide determination in wastewater (Gil et al., 2003).

Sulfur species were nearly completely removed from the wastewater during MFC operation. This approach represents a potential solution for simultaneous electricity production and removal of sulfur-based pollutants (including organic sulfur compounds if 
they are reducible to sulfide by bacteria), and offers a technological tool both for sustainable energy generation and for economic and efficient removal of sulfur pollutants.

\section{Acknowledgements}

This research was supported by the Engineering and Physical Sciences Research Council (UK) as part of the Supergen5 Biological Fuel Cells Consortium (EPSRC contract: EP/D047943/1). The authors thank Dr. Daniel Driscoll for the assistance in ion chromatography, Mr. Paul Leahy for the fuel cell construction and MAST Carbon for provision of ACC samples.

\section{Appendix A. Supplementary data}

Supplementary data associated with this article can be found in the online version. 


\section{Reference}

Aelterman, P., Freguia, S., Keller, J., Verstraete, W., Rabaey, K., 2008. Appl. Microbiol. Biotechnol. 78, 409-418.

Barrett, E.P., Joyner, L.S., Halenda, P.P., 1951. J. Am. Chem. Soc. 73, 373-380.

Battersby, N.S., 1988. In: Austin B. (Ed.), Sulphate-reducing bacteria, Methods on aquatic bacteriology, John Wiley \& Sons, New York, pp. 269-299.

Biffinger, J.C., Ray, R., Little, B., Ringeisen., B.R., 2007. Environ. Sci. Technol. 41, $1444-1449$.

Brunauer, S., Emmett P. H. and Teller E., 1938, J. Amer. Chem. Soc., 60, 309-319.

Cheng, S, Liu, H., Logan, B., 2006. Environ. Sci. Technol. 40, 364-369.

Cooney, M.J., Roschi, E., Marison, I.W., Comninellis, Ch., Stockar, U., 1996. Enzyme Microb. Technol. 18, 358-365.

Dannenberg, S., Kroder, M., Dilling, W., Cypionka, H., 1992. Arch. Microbiol. 158, 9399.

Fan, Y.Z., Hu, H.Q., Liu, H., 2007. J. Power Sources 171, 348-354.

Gil, G.C., Chang, I.S., Kim, B.H., Kim, M., Jang, J.K., Park, H.S., Kim, H.J., 2003. Biosens. Bioelectron. 18, 327-334.

Habermann, W., Pommer, E.-H., 1991. Appl. Microbiol. Biotechnol. 35, 128-133.

Harnisch, F., Schröder, U., Scholz, F., 2008. Environ. Sci. Technol. 42, 1740-1746.

Ieropoulos, I., Greenman, J., Melhuish, C., Hart, J., 2005. J. Power Sources 145, 253-256.

Kim, J.R., Oh, S.-E., Cheng S., Logan B.E., 2007. Environ. Sci. Technol. 41, 1004-1009.

Lens, P.N.L., Hulshoff Pol, L.W., 2000. Environmental technologies to treat sulfur pollution: Principles and engineering, IWA, London.

Liu, H., Logan, B., 2004. Environ. Sci. Technol. 38, 4040-4046.

Mohan, S.V., Raghavulu, S.V., Sarma, P.N., 2008, Biosens. Bioelectron. 23, 1326-1332. 
Rabaey, K., Boon N., Siciliano, S. D., Verhaege, M., Verstraete, W., 2004. Appl. Environ. Microbiol. 70, 5373-5382.

Reis, M.A.M., Almeida, J.S., Lemos, P.C., Carrondo, M.J.T., 1992. Biotechnol. Bioeng. 40, 593-600.

Ter Heijne, A., Hamelers, H.V.M., De Wilde, V., Rozendal, R.A., Buisman, C.J.N. 2006. Environ. Sci. Technol. 40, 5200-5205.

Varcoe, J.R., Slade, R.C.T., Wright, G.L., Chen, Y.L., 2006. J. Phys. Chem. B 110, 21041-21049.

Widdel, F., Pfennig, N., 1984. In: Krieg N. R., Holt J.G. (Ed.), Dissimilatory sulfate- or sulfur-reducing bacteria, Bergey's manual of systematic bacteriology. The Williams \& Wilkins, Baltimore. pp. 663-679.

Zhao, F., Harnisch, F., Schröder, U., Scholz, F., Bogdanoff, P., Herrmann, I., 2005. Electrochem. Commun. 7, 1405-1410.

Zhao, F., Harnisch, F., Schröder, U., Scholz, F., Bogdanoff, P., Herrmann, I., 2006. Environ. Sci. Technol. 40, 5193-5199.

Zhao, F., Rahunen, N., Varcoe, J.R., Chandra, A., Avignone-Rossa, C., Thumser, A.E., Slade, R.C.T., 2008. Environ. Sci. Technol. 42 (13), 4971-4976.

Zhao, F., Wang, M.K., Dong, S.J., 2004a. Electrochem. Solid State Lett. 7, E48-E50.

Zhao, F., Wu, X.E, Wang, M.K., Liu, Y., Gao, L.X., Dong, S.J., 2004b. Anal. Chem. 76, 4960-4967. 


\section{Captions}

Fig. 1. Schematic of the laboratory scale MFC prototype: one chamber and dual cathode assembly. RE: reference electrode; PEM: proton exchange membrane.

Fig. 2. SEM characterization of ACC. a) activated carbon cloth and b) cluster. The insets are magnified views of individual fibres in ACC.

Fig. 3. Open circuit potential of a cathode assembly recorded versus time. Inset is galvanodynamic polarization plots of the air-breathing cathode assembly. The assembly was placed at the end of an MFC chamber filled with bacteria-free phosphate buffer (50 mmol dm $\mathrm{dm}^{-3}, \mathrm{pH}=7$ ). The arrows show the times for galvanodynamic polarization tests.

Fig. 4. Open circuit potentials of anodes recorded with time. The ACC and the CFV were placed in $100 \mathrm{~cm}^{3}$ wastewater inoculated with $1 \mathrm{~cm}^{3}$ D. desulfuricans culture in a sealed chamber. Geometrical area of electrodes was $20 \mathrm{~cm}^{2}$.

Fig. 5. Current $v s$. time performance of a single chamber, continuous flow MFC using an ACC-CFV composite anode and dual cathode assembly. The inset shows an expanded representation of the first $5000 \mathrm{~s}$ of the test. The MFC was operated at open circuit for the first $500 \mathrm{~s}$ and then an external load of $20 \mathrm{ohm}$ was applied. Geometrical area of anode and of cathode were 140 and $18 \mathrm{~cm}^{2}$, respectively. 
Table 1. Concentration changes of sulfur compounds in artificial wastewater.

\begin{tabular}{lccc}
\hline & Before experiment & After experiment $^{\mathrm{a}}$ & Removal efficiency \\
\hline Sulfite $/ \mathrm{g} \mathrm{dm}^{-3}$ & 1.27 & $0.11 \pm 0.05$ & $91 \%$ \\
Thiosulfate $/ \mathrm{g} \mathrm{dm}^{-3}$ & 1.13 & $0.16 \pm 0.13$ & $86 \%$ \\
Sulfate $/ \mathrm{g} \mathrm{dm}^{-3}$ & 0.026 & n.d. & $\sim 99 \%{ }^{\mathrm{b}}$ \\
\hline a: after $22 \mathrm{~h}$ of the MFC operation; b: ref. results (Zhao et al, 2008); n.d. $=$ none detected
\end{tabular}




\section{Anode}

Cathode

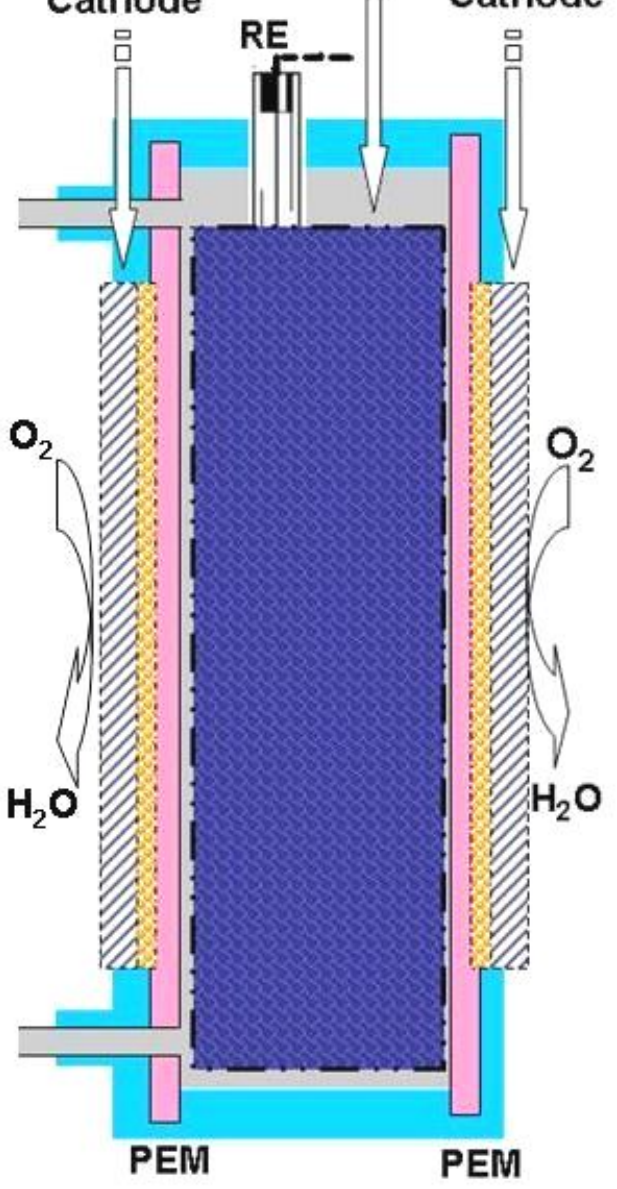




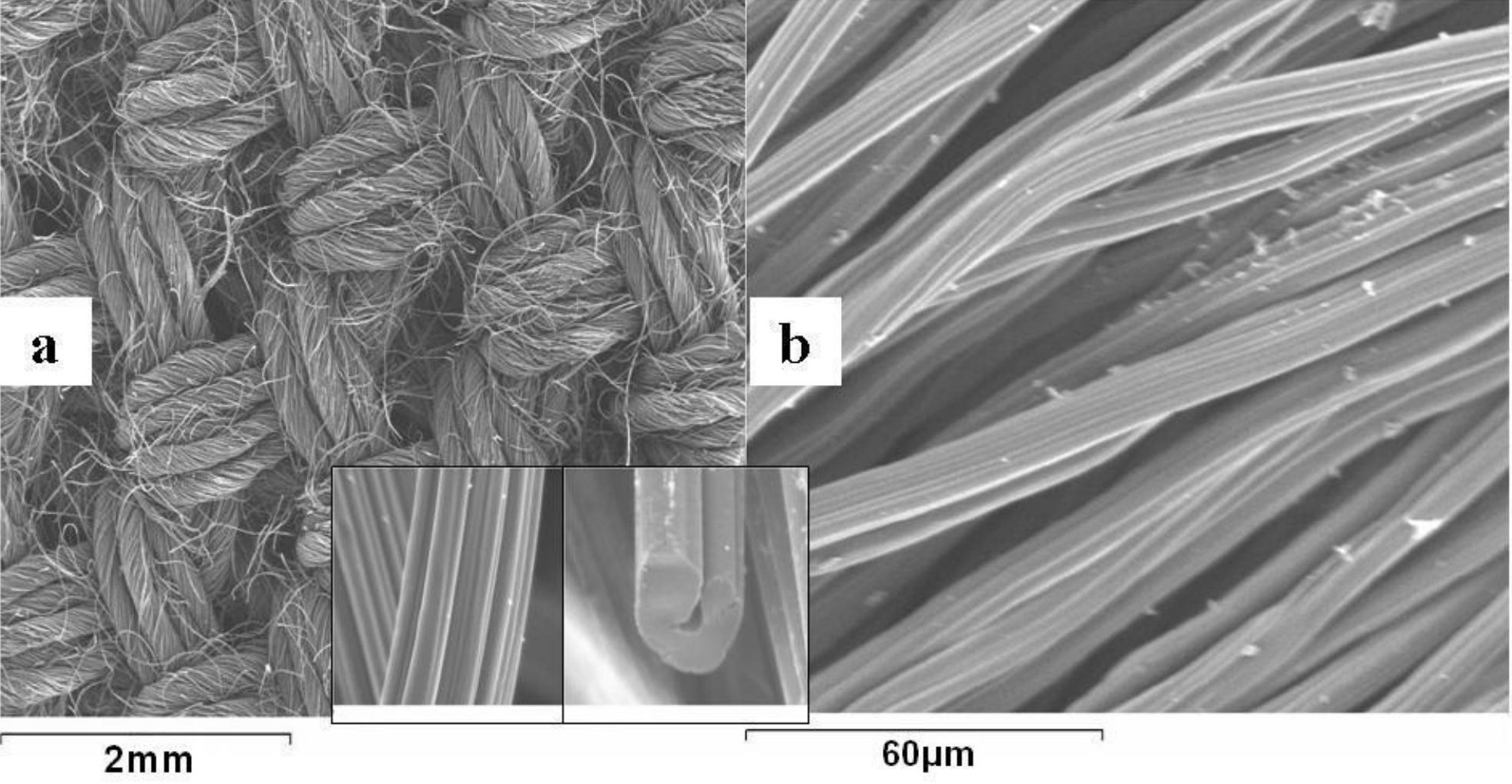




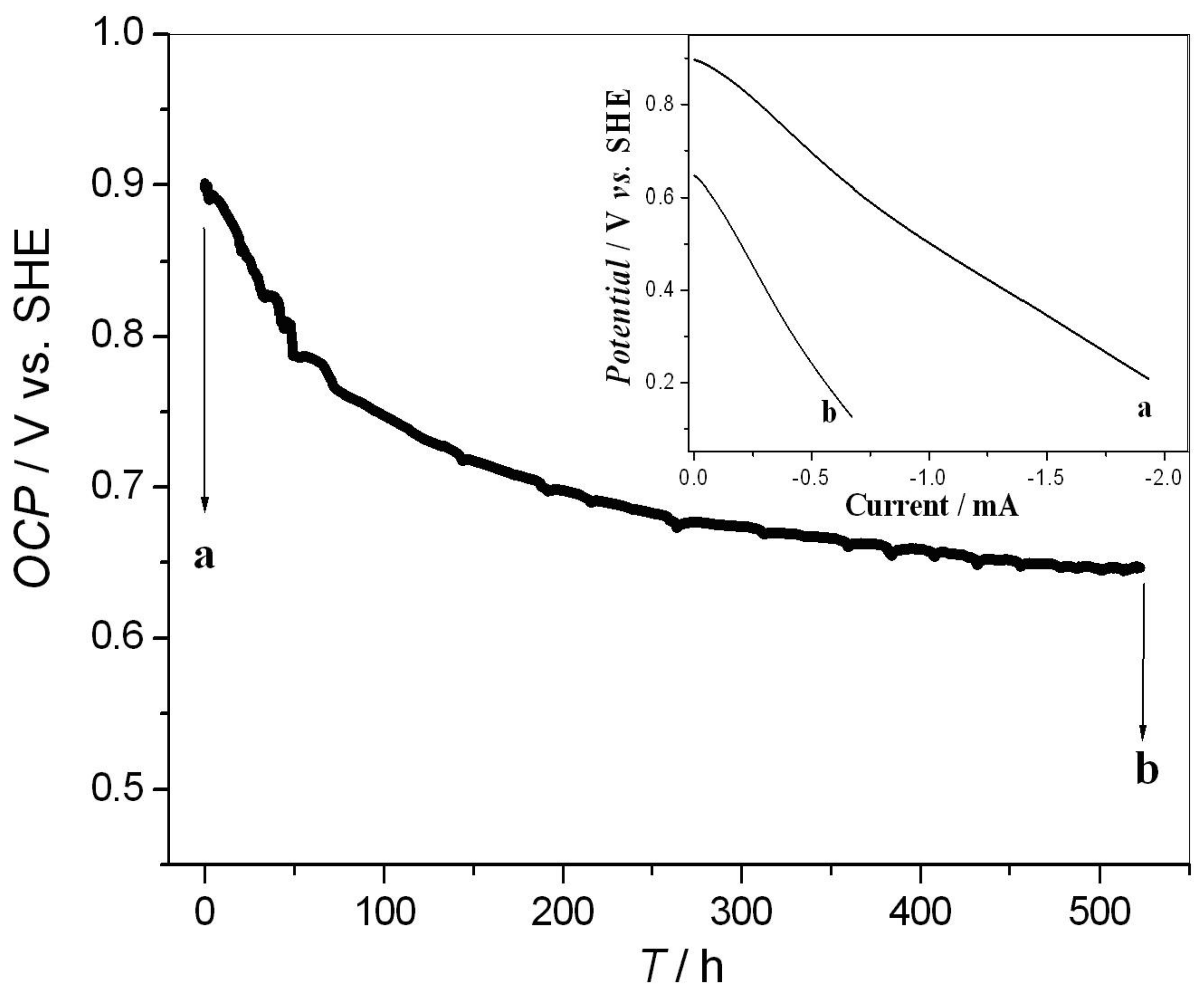




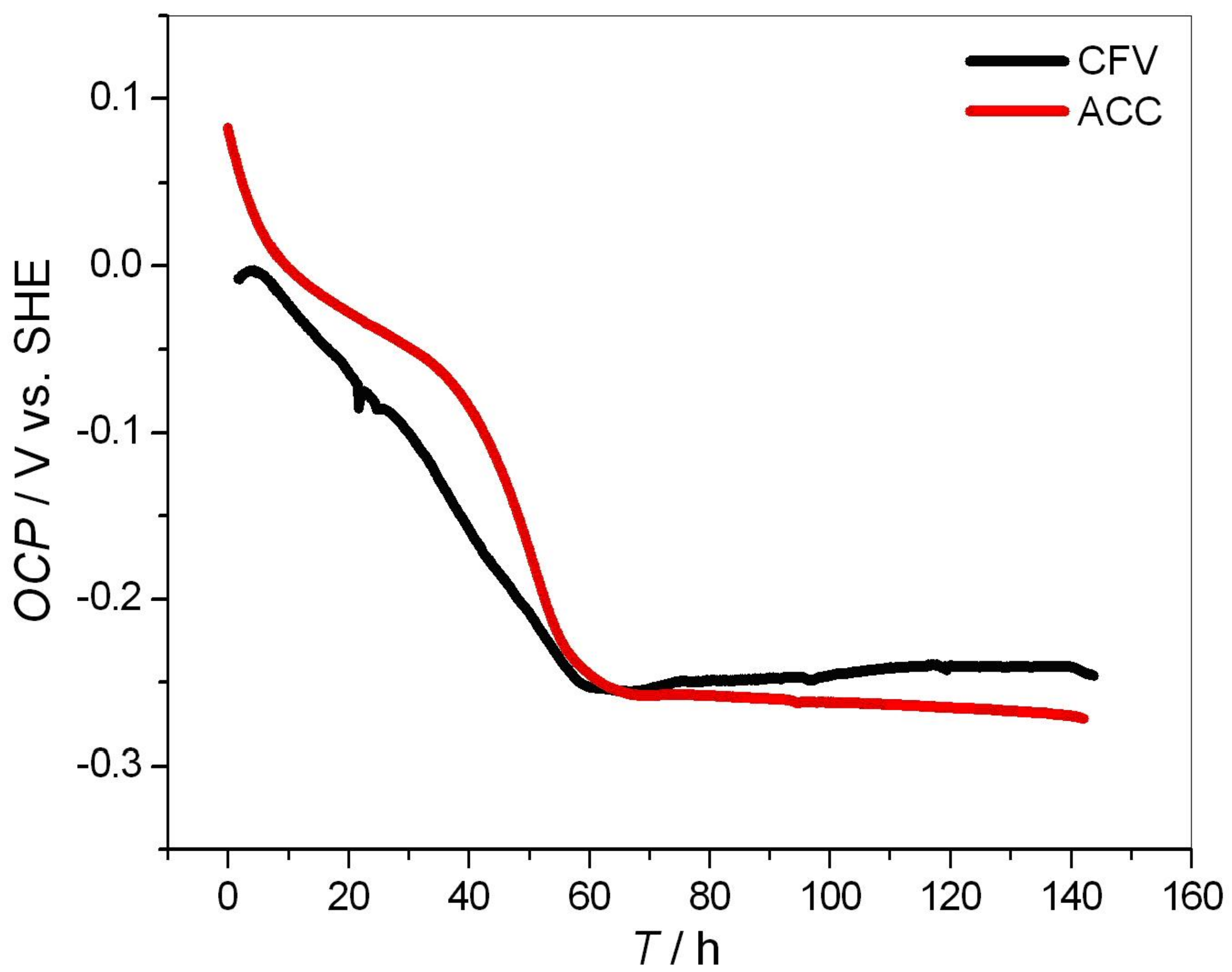




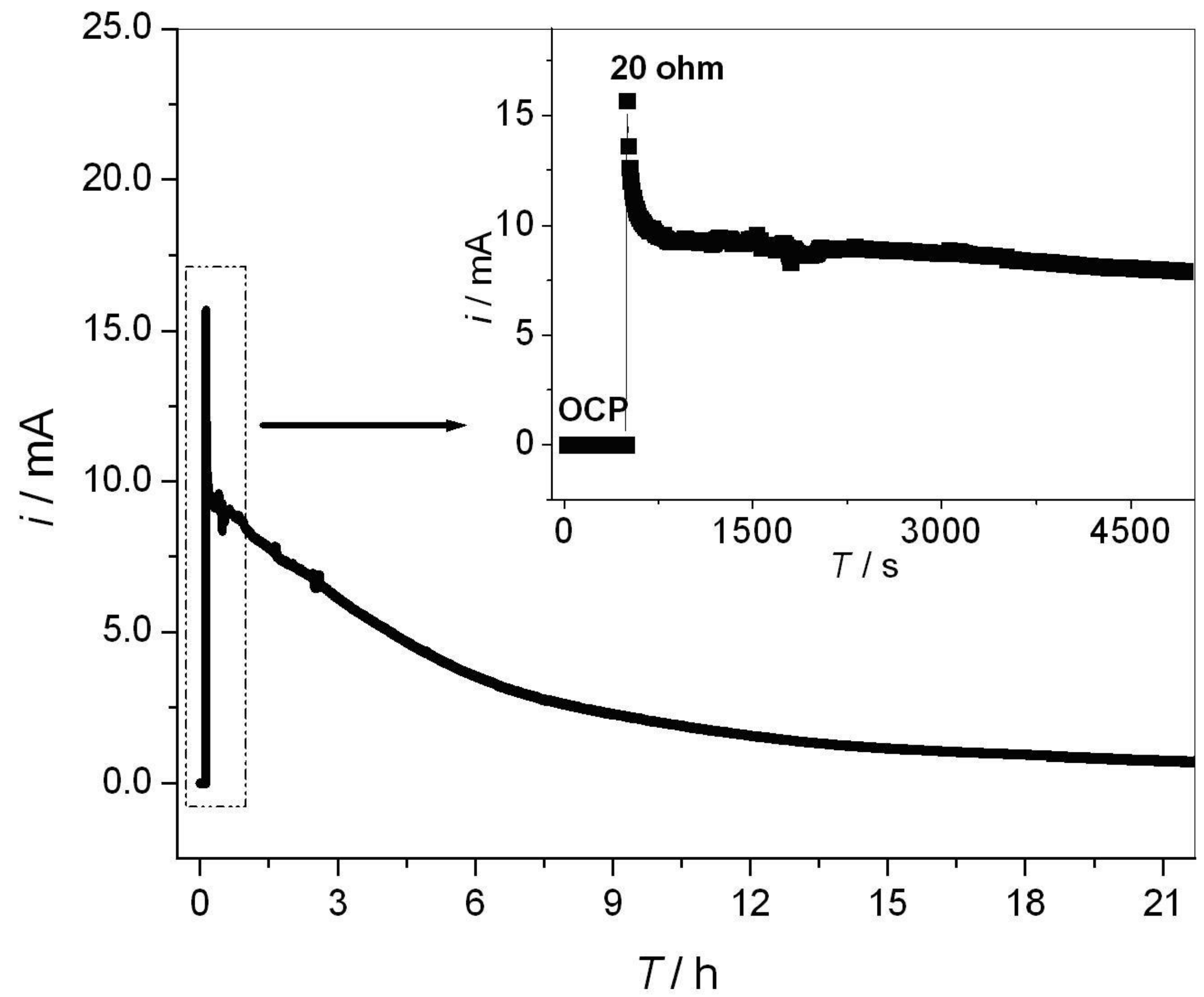


Supplementary data:

\section{Factors affecting the performance of microbial fuel cells for sulfur pollutants removal}

Feng Zhao ${ }^{a}$, Nelli Rahunen ${ }^{b}$, John R. Varcoe $^{a}$, Alexander J. Roberts ${ }^{\mathrm{a}}$, Claudio Avignone-Rossa $^{b}$, Alfred E. Thumser ${ }^{b}$, Robert C.T. Slade ${ }^{a}$

${ }^{a}$ Chemical Sciences, ${ }^{b}$ Biological Sciences,

University of Surrey, Guildford, GU2 7XH, United Kingdom

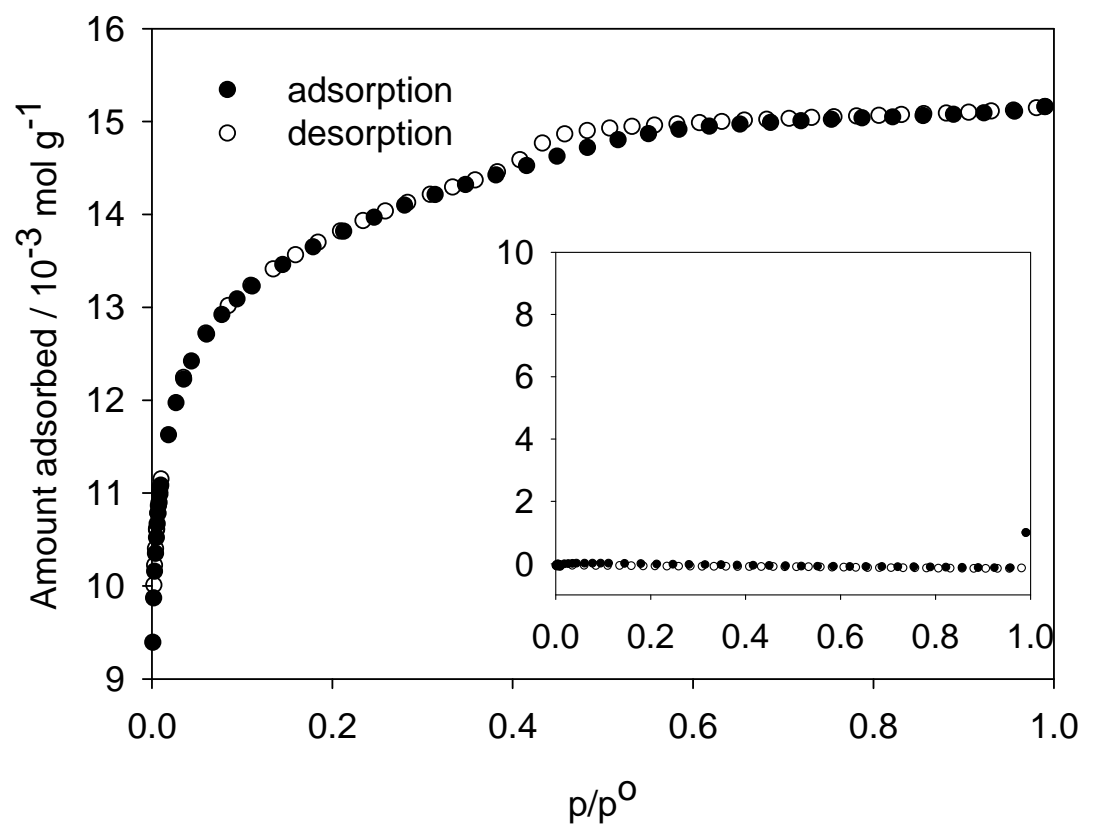

S-Fig. 1. Nitrogen sorption isotherms of the different carbon based materials, ACC and CFV (inset), at 77 K. Filled symbols: adsorption; open symbols: desorption. 
S-Table 1. Summary of the ACC and CFV materials properties.

\begin{tabular}{lcc}
\hline & ACC & CFV \\
\hline BET specific surface area $\left(\mathrm{m}^{2} \mathrm{~g}^{-1}\right)$ & 1038 & $<0.3$ \\
Total pore volumes $\left(\mathrm{cm}^{3} \mathrm{~g}^{-1}\right)$ & 0.53 & $<0.03$ \\
Modal pore size $(\AA)$ & 36.5 & - \\
Thickness $(\mathrm{mm})$ & 0.55 & 0.10 \\
Conductivity $\left(\mathrm{S} \mathrm{cm}^{-1}\right)$ & 0.07 & 0.06 \\
\hline
\end{tabular}

